\title{
False-positive axillary lymphadenopathy due to silicone granuloma on FDG PET/CT
}

\author{
Chirag N. Patel • Ruth E. Macpherson • \\ Kevin M. Bradley
}

Received: 28 June 2010 /Accepted: 23 August 2010 /Published online: 15 September 2010

(C) Springer-Verlag 2010

A 50-year-old woman with a left breast implant following mastectomy for breast carcinoma 14 years previously underwent ${ }^{18} \mathrm{~F}$-FDG PET/CT to stage a newly diagnosed cervical carcinoma. The MIP image (a) demonstrates a markedly FDG-avid primary cervical tumour (short arrow) and extensive FDG-avid pelvic and para-aortic lymphadenopathy (arrowheads). In addition, there is a cluster of FDG-avid left axillary lymph nodes (long arrow) which were suspicious for nodal metastatic disease from the new cervical or previous breast carcinoma. The axial fused PET/CT image (b) confirms a FDG-avid axillary lymph node (arrow) and left breast "Becker implant" in situ (arrowheads) which is a double-lumen prosthesis consisting of a fixed outer silicone component and expandable inner saline-filled lumen. Subsequent fine-needle aspiration of a left axillary node (c) shows refractile material within the extracellular spaces and multinucleate foreign body giant cells in keeping with silicone granuloma [1].

Granuloma formation is a natural host reaction to foreign material and is commonly found following direct silicone injections into the breast or extracapsular silicone implant rupture [2]. Granulomas are usually found within the breast parenchyma, but silicone may migrate to local lymph nodes and other distant sites including the pleura, ribs, upper arm musculature and even within the abdomen [3]. Silicone lymphadenopathy has been reported in a small number of patients in the absence of apparent implant rupture suggesting that "gel bleed" of silicone may also cause these reactions $[4,5]$. False-positive FDG uptake is wellrecognized in granulomatous processes and as such, silicone

C. N. Patel $(\triangle) \cdot$ R. E. Macpherson $\cdot$ K. M. Bradley Department of Nuclear Medicine, Churchill Hospital, Old Road, Headington,

Oxford OX3 7LJ, UK

e-mail: chiragpatel@doctors.org.uk

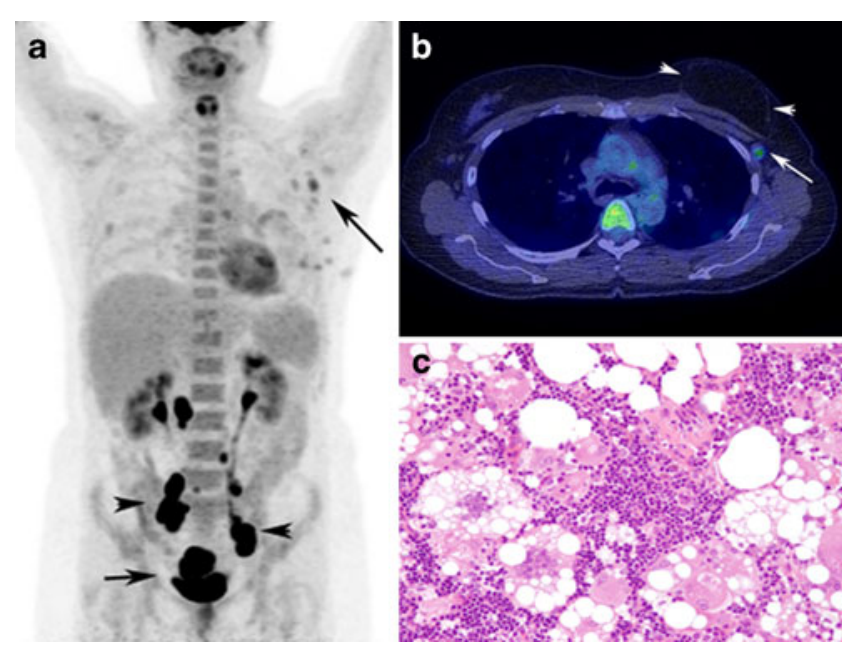

granulomas may be mistaken for nodal metastatic disease in patients with breast carcinoma on FDG PET/CT.

Conflicts of interest None.

\section{References}

1. Tabatowski K, Elson CE, Johnston WW. Silicone lymphadenopathy in a patient with a mammary prosthesis. Fine needle aspiration cytology, histology and analytical electron microscopy. Acta Cytol 1990;34:10-4.

2. van Diest PJ, Beekman WH, Hage JJ. Pathology of silicone leakage from breast implants. J Clin Pathol 1998;51:493-7.

3. Brown SL, Silverman BG, Berg WA. Rupture of silicone-gel breast implants: causes, sequelae and diagnosis. Lancet 1997;350:1531-7.

4. Truong LD, Cartwright J Jr, Goodman MD, Woznicki D. Silicone lymphadenopathy associated with augmentation mammaplasty. Morphologic features of nine cases. Am J Surg Pathol 1988;12:484-91.

5. Santos-Briz A Jr, López-Ríos F, Santos-Briz A, De Agustín PP. Granulomatous reaction to silicone in axillary lymph nodes. A case report with cytologic findings. Acta Cytol 1999;43:1163-5. 